Short communication

\title{
Monitoring proliferative activities of hormone-like odorants in human breast cancer cells by gene transcription profiling and electrical impedance spectroscopy
}

\author{
Horst Pick $^{\mathrm{a}, *}$, Samuel Terrettaz ${ }^{\mathrm{a}}$, Olivia Baud ${ }^{\mathrm{a}}$, Ouahiba Laribi ${ }^{\mathrm{b}}$, Cathrin Brisken ${ }^{\mathrm{b}}$, \\ Horst Vogel ${ }^{\mathrm{a}, * * *}$ \\ a Laboratory of Physical Chemistry of Polymers and Membranes, Institute of Chemical Sciences and Engineering, Ecole Polytechnique Fédérale de Lausanne \\ (EPFL), CH-1015 Lausanne, Switzerland \\ ${ }^{\mathrm{b}}$ ISREC-Swiss Institute for Experimental Cancer Research, NCCR Molecular Oncology, Ecole Polytechnique Fédérale de Lausanne (EPFL), CH-1015 Lausanne, \\ Switzerland
}

\section{A R T I C L E I N F O}

\section{Article history:}

Received 3 April 2013

Received in revised form

21 June 2013

Accepted 24 June 2013

Available online 4 July 2013

Keywords:

Estrogenic chemicals

Estrogen receptor $\alpha(E R \alpha)$

Cell proliferation

Electrical cell substrate impedance sensing

(ECIS)

Synthetic sandalwood odorants

Signal transduction

Transcription

Breast cancer

\begin{abstract}
A B S T R A C T
The human estrogen receptor alpha (ER $\alpha)$ mediates the proliferative action of hormones in breast cancer cells by regulating the expression of target genes to control cellular functions. Current methodologies do not permit a real-time assessment of these processes in living cells. We overcome this limitation using electrical cell-substrate impedance sensing for measuring ER $\alpha$-regulated signaling processes indicative of the onset of cell proliferation to target them for compound screenings. We report that hormone like odorants regulate, similarly as natural estrogen, ER $\alpha$-mediated gene expression involved in mitogenic and developmental processes in MCF7 breast cancer cells. An odorant concentration-dependent switch in cell responses was detectable already 10-15 h post-stimulation, providing rapid quantification of hormonal activity before cell division occurred. Though ER $\alpha$ exhibits complex regulatory roles our noninvasive approach captures its activity for accelerated screenings of compounds promoting breast cancer cell proliferation expanding the analysis of ER $\alpha$ signaling networks.
\end{abstract}

(c) 2013 Elsevier B.V. All rights reserved.

\section{Introduction}

Estrogens are steroid hormones that play a fundamental role in the physiology of various human tissues, but they are also critical for the initiation and progression of breast and gynecological cancers (Conzen, 2008). Their small size and lipophilic properties allow them to freely traverse the plasma membrane and to directly influence target cells (Pick et al., 2007). Estrogen functions are mediated by estrogen receptors (ERs), members of the nuclear hormone receptor family. They primarily act as ligand-inducible transcription factors to modulate the expression of specific genes, which regulate multiple body functions (Kininis and Kraus, 2008).

There are two main human ER subtypes, ER $\alpha$ and ER $\beta$, which exhibit distinct tissue-specific expression patterns and biological roles (Thomas and Gustafsson, 2011). Generally ERs can form homo- and heterodimers before binding to specific DNA sequences called

\footnotetext{
* Corresponding author. Tel.: +41 21693 3132; fax: +41 216936190 .

*** Corresponding author. Tel.: +41 21693 3155; fax: +41 216936190.

E-mail addresses: horst.pick@epfl.ch (H. Pick), horst.vogel@epfl.ch (H. Vogel).
}

estrogen response elements (EREs), influenced by diverse sets of ER-interacting proteins that have been described as co-activators or co-repressors to enhance or suppress transcription activity of target genes (Metivier et al., 2003). ERs can also indirectly bind to alternative sites at gene promoters and affect transcription by associating with stimulating protein-1 (SP1), activator protein-1 (AP1), or other transcription factors (Marino et al., 2006). Finally, gene regulation may even occur through rapid signaling of membrane-associated ERs. These pathways involve kinase cascades and second messenger signaling, which indirectly impact transcription and contribute to the overall diversity and complexity of cellular processes influenced by estrogens (Marino et al., 2006).

ER $\alpha$ is the most abundant ER and an important determinant of breast cancer biology and treatment as well as a prognostic marker (Giacinti et al., 2006). It exhibits high specificity and affinity for its endogenous ligand $17 \beta$-estradiol (E2) but also binds a wide range of compounds with strikingly diverse structures (Brzozowski et al., 1997). These include natural products and synthetic chemicals that may not share any obvious structural similarity to E2, precluding prediction of their estrogenic activities on gene regulation and potential adverse health effects on the basis of chemical structure (Agatonovic-Kustrin et al., 2008). 
An ER $\alpha$ positive human breast cancer cell line (MCF7) currently serves as the most prominent model system for studying breast cancer progression and for detecting chemicals with estrogenic activities (Soto et al., 1995). The number of genes regulated by E2 in MCF7 cells, ranges from 100 to 1500 . These largely appear to be involved in signaling pathways controlling cell proliferation, invasion and metastasis (Kininis and Kraus, 2008; Abba et al., 2005). The finding that E2 also exhibits similar gene regulation in native human tumors further validates MCF7 cells as an estrogen signaling model system relevant to breast cancers (Creighton et al., 2006). The mitogenic response of MCF7 cells to estrogenic compounds is considered to be the most sensitive, specific, and biologically relevant hallmark of estrogenic activity (Fang et al., 2000). Influences of chemicals on MCF7 cell proliferation are usually assayed over a time period of 4-6 days, sometimes even up to 14 days (Soto et al., 1995; Charles and Darbre, 2009). This time consuming approach does not allow for rapid screening of a large number of compounds.

Here we investigated cellular processes preceding the onset of proliferation with the aim of discovering novel and more rapid indicators of estrogenic activity. We focused on estrogenic sandalwood odorants, which are widely-used in perfumes and fragranced body care products. Elsewhere, we demonstrated their proliferative effects in MCF7 cells mediated by ER $\alpha$ (Pick et al., 2009). Here, we investigated the effects of sandalwood odorants on the regulation of gene transcription and activation of cellular signaling pathways. Such experiments are of importance for better defining the role of synthetic odorants as activators of ER $\alpha$ as well as their estrogenic potency in regulating cellular functions. Whereas the impact of E2 on transcription regulation has been worked out in considerable detail (Hah et al., 2011), very little is known about the timing and extent to which estrogen-like chemicals, especially synthetic odorants interfere with these processes.

To investigate the correlation between ER $\alpha$-mediated genomic effects and their phenotypic cellular responses induced by sandalwood odorants, we used electrical cell substrate impedance sensing (ECIS) on cultured MCF7 cells. ECIS is based on the principle that cells attaching to the electrode act as insulators increasing the electrical impedance of the electrode (Giaever and Keese, 1991). The measured impedance depends on (i) the number of cells covering the electrode, (ii) the strength of cell attachment, and (iii) the cells' morphology. Stimulation of endogenous ER $\alpha$ by compound application activates various cell functions leading to morphological changes of the cells, which in turn induce changes in the local ionic environment at the interface between the electrode and the cells, and thereby modulate the electrode's impedance. Here, we demonstrate that ECIS is suited for rapid detection of estrogenic actions and thus enables accelerated compound screening.

\section{Materials and methods}

\subsection{Chemicals and reagents}

The following odorants were from Givaudan and Sigma: 3,3Dimethyl-5-(2,2,3-trimethyl-3-cyclopenten-1-yl)-4-penten-2-ol, (Polysantol, PS); 1-Methyl-2-[(1,2,2-trimethylbicyclo[3.1.0]-hex-3-ylmethyl) cyclopropyl]methanol, (Javanol, JV); Methyl 2,4-dihydroxy-3,6-dime thylbenzoate, (Mousse Cristal, MC): these compounds were freshly dissolved in DMSO before experiments. ICI 182,780 was from Tocris Biosciences, and $17 \beta$-estradiol (E2) was from Sigma.

\subsection{Cell culture}

MCF7 human breast cancer cells (gift from Ana Soto, Tufts University, Boston) are dependent on estrogen for proliferation (Soto et al., 1995) and were grown as stock cultures in Dulbecco's modified Eagle's medium (DMEM, Invitrogen) supplemented with $5 \%$ fetal bovine calf serum (Invitrogen) at $37{ }^{\circ} \mathrm{C}$ in $5 \% \mathrm{CO}_{2}$ atmosphere and saturating humidity. For hormone depletion, cells were maintained in phenol-red free DMEM supplemented with $10 \%$ of charcoal dextran-treated calf serum (HyClone) for at least 2 days before an experiment.

\subsection{Real-time reverse transcription polymerase chain reaction (RT-PCR)}

MCF7 cells were seeded into 6-well plastic tissue culture dishes at a concentration of $5 \times 10^{3}$ cells/well in $5 \%$ charcoal-treated fetal bovine serum in DMEM. After $24 \mathrm{~h}$ at $37{ }^{\circ} \mathrm{C}$ with $5 \% \mathrm{CO}_{2}$ the seeding medium was removed and replaced by the experimental medium (phenol red-free DMEM, 5\% charcoal/dextran-treated, heatinactivated human serum, from Sigma) supplemented with the appropriate concentrations of a particular odorant or a mixture of an odorant and the ER-specific antagonist ICI 182,780 $(10 \mu \mathrm{M})$ (Tocris Bioscience). The assay was terminated by removing the cell media from the wells and freezing the culture dishes at $-80^{\circ} \mathrm{C}$. For realtime RT-PCR total RNA was extracted with chloroform and processed with the RNeasy Kit (Qiagen). Total RNA was reverse transcribed using RT (Life Technology) and random hexamers (Roche). Semiquantitative real-time PCR analysis was performed with SYBR Green PCR Core Reagents system (Qiagen) on a realplex2 Mastercycler PCR Detection System (Eppendorf) using primers and conditions provided elsewhere (Ciarloni et al., 2007; Ayyanan et al., 2011).

\subsection{Cellular impedance assay}

The electrical impedance of MCF7 cells cultured on an array of microelectrodes integrated at the bottom of individual compartments of a 96-well E-plate (xCelligence sytem, Roche) was measured. Cells attaching to the electrode act as insulators, and increase the electrical impedance of the electrode. Stimulation of endogenous ER $\alpha$ by compound application activates various cell functions leading to morphological changes of the cells, which in turn finally induce changes in the local ionic environment at the electrode/cell interface, and modulate the electrode impedance, displayed by the cell impedance index $(\mathrm{CI})$. The $\mathrm{CI}$ is a dimensionless parameter calculated as the difference between the impedance of cell-covered and cell-free electrodes measured at $10 \mathrm{kHz}$ and divided by a frequency factor $(R=15 \Omega)$. For a better comparison of impedance responses between different samples, the measured cell impedance indices within a time series of one sample were normalized by the particular value measured at the time of addition of odorants. This procedure corrected for minimal differences in cell growth between the samples in the different wells. Furthermore, from each normalized $\mathrm{CI}$ value the particular $\mathrm{Cl}$ value before (or with the lowest) stimulation was subtracted to highlight the estrogenic effects. After this double correction, data were referred to as "baseline normalized cell indices". Typically 30,000 cells were seeded per well in DMEM medium with $10 \%$ of charcoal/dextran-treated, heatinactivated human serum, $15 \mathrm{mM}$ HEPES and $100 \mu \mathrm{g} / \mathrm{ml}$ penicillinstreptomycin (Invitrogen) and grown for $16-20 \mathrm{~h}$ before ligand addition. Electrical impedance values were recorded continuously every 30 min. Finally, the estrogenic effect was obtained by fitting the baseline normalized cell indices with a Langmuir equation using both the maximal impedance amplitudes reached after $40-50 \mathrm{~h}$ and the slope of the early linear ascending phase observed 10-24 h after stimulation. Curve fitting was performed using Igor software (Wavemetrics). All data represent means of at least three independent experiments. 


\section{Results}

3.1. Real-time RT-PCR analysis of odorant-mediated gene expression profiles

We assessed the ability of the fragrance odorants Javanol (JV), Polysantol (PS), and Mousse Cristal (MC), (chemical structures depicted in Fig. 1A) to regulate expression of several established estrogen-responsive genes in MCF7 cells. Transcription of genes for progesterone receptor (PR), amphiregulin (AR), ER $\alpha$, and wingless-type MMTV integration site family, member 4 (Wnt4) was quantified over time. All of these proteins play critical roles in cell proliferation and mammary gland development (Ciarloni et al., 2007; Brisken et al., 2000; Brisken and O'Malley 2010).

After 7 days of estrogen deprivation, MCF7 cells were exposed to a particular odorant (always at $100 \mu \mathrm{M}$ ) for distinct time periods between $30 \mathrm{~min}$ and $8 \mathrm{~h}$. Total RNA extracts of these cells were analyzed using real-time reverse transcription PCR (RT-PCR) and compared to RNA samples from cells which were stimulated with $1 \mathrm{nM} \mathrm{E2}$ for $4 \mathrm{~h}$ and $8 \mathrm{~h}$. Our results indicate that odorantmediated effects on gene regulation compare well to those elicited by the natural hormone (Fig. 1).

Transcripts of PR, WNT4 and AR were up-regulated whereas ER $\alpha$ was down-regulated by all of the odorants. JV and PS increased transcription of PR and AR to the same high extent as E2, whereas WNT4 mRNA was slightly less up-regulated ( $~ 60 \%$ of the transcript level obtained for E2). Within 1-2 h after odorant stimulation changes in transcript levels were observed, which continued to increase over time.

MC evoked significantly lower gene regulatory effects indicating weaker estrogenic activity. The effects of odorants and E2 on transcription were inhibited by the antiestrogenic compound ICI 182,780 suggesting the involvement of an ER $\alpha$ mediated mechanism. We next investigated the time required for genomic effects to manifest into measurable phenotypic changes after odorant application by employing electrical impedance sensing as a noninvasive technique to capture the global cellular responses in real-time.

\subsection{Impedance responses reveal different signatures of estrogenic odorants}

The interactions of cells with underlying electrodes were followed by electrical impedance spectroscopy at $10 \mathrm{kHz}$ (details in: supplementary Note 1, Fig. S1, and Table S1). In the initial phase $(\sim 20 \mathrm{~h})$ after seeding MCF7 cells adhered and spread on sensing electrodes. This resulted in a slight increase of impedance values over time with similar kinetics for all cell samples (Fig. 2A). As the electrical impedance detects with high sensitivity small cell morphological changes (Giaever and Keese, 1991), which are directly related to alterations in cellular activities, it allows cellular signaling to be quantified (Yu et al., 2006).

After electrode adherent cells were exposed to $0.1 \mathrm{nM}$ of the natural hormone E2 or $50 \mu \mathrm{M}$ of the odorants PS and JV, an exponential increase of the impedance was observed. The impedance responses to E2 and the odorants PS and JS closely resembled each other with respect to curve shape, kinetics, and amplitudes (Fig. 2A). A slight increase in impedance upon addition of apparently hormone-free cell medium indicated a minor background cell proliferation, which might be induced by traces of hormones remaining in the serum supplemented to the medium. This effect was largely suppressed by the addition of the antagonist ICI 182,780 (Fig. 2A). When essential nutrients became depleted, the impedance leveled off and then decreased due to lower cell adhesion. Compared to the other odorants, MC $(100 \mu \mathrm{M})$ showed a different impedance signature with a delayed response.
A

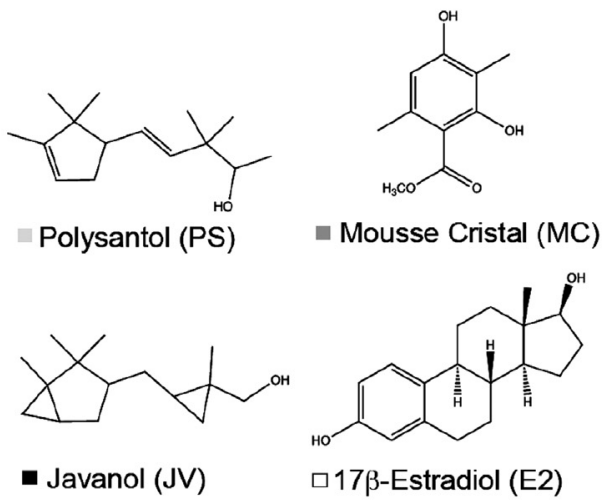

B

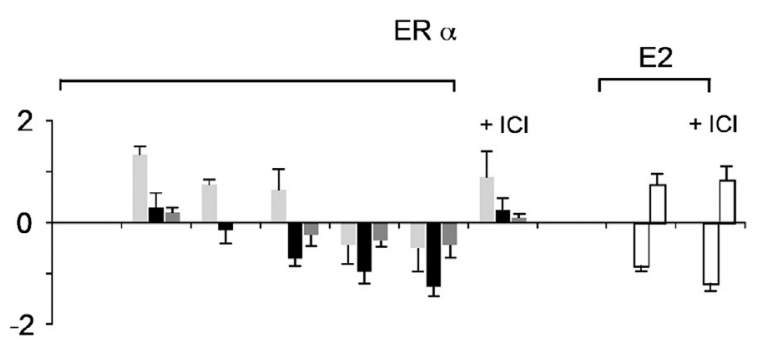

PR
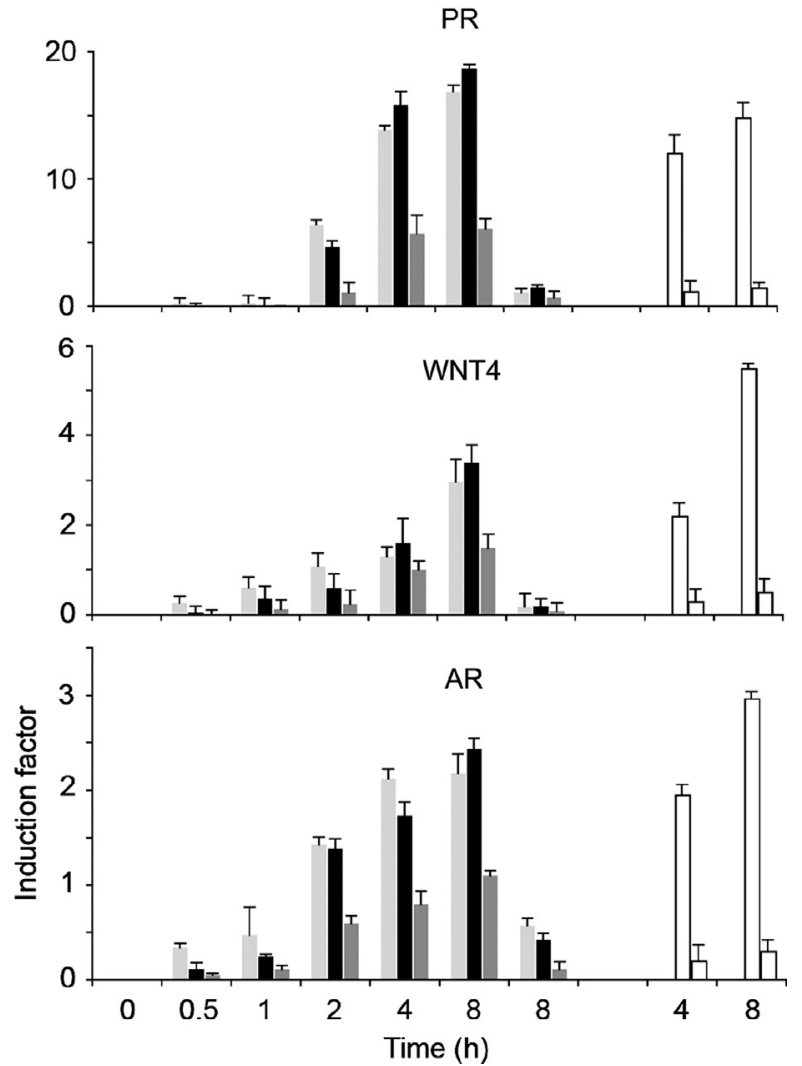

Fig. 1. RT-PCR reveals similarities in patterns of gene expression induced by odorants and E2 in MCF7 cells. (A) Hormone-depleted MCF7 cells expressing endogenous ER $\alpha$ were challenged with the odorants Polysantol (PS, $100 \mu \mathrm{M})$, Javanol $(J V, 100 \mu \mathrm{M})$, Mousse Cristal $(\mathrm{MC}, 100 \mu \mathrm{M})$ and with E2 $(1 \mathrm{nM})$ for the indicated times in B. (B) Total RNA was extracted from all samples and real-time RT-PCR revealed transcription up-regulation of PR, WNT4 and AR and the downregulation of ER $\alpha$ by the estrogenic odorants (left) and E2 (right). The inhibition of ER $\alpha$-mediated transcription by co-application of the anti-estrogenic compound ICI $182,780(10 \mu \mathrm{M})$ for $8 \mathrm{~h}$ is shown for each odorant and E2. Measurements are subtracted with the background transcription value obtained before ligand application and are given as induction factor relative to the endogenous control transcript TBP (TATA-box binding protein). Data represent means and standard deviations of three independent experiments. 
A

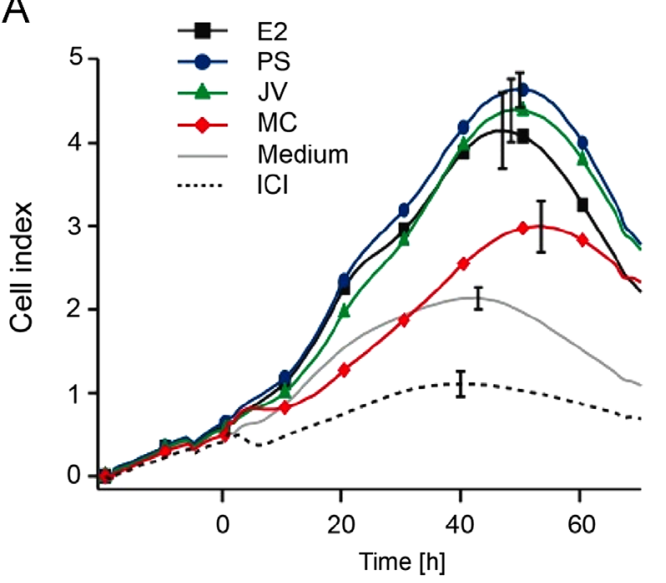

B
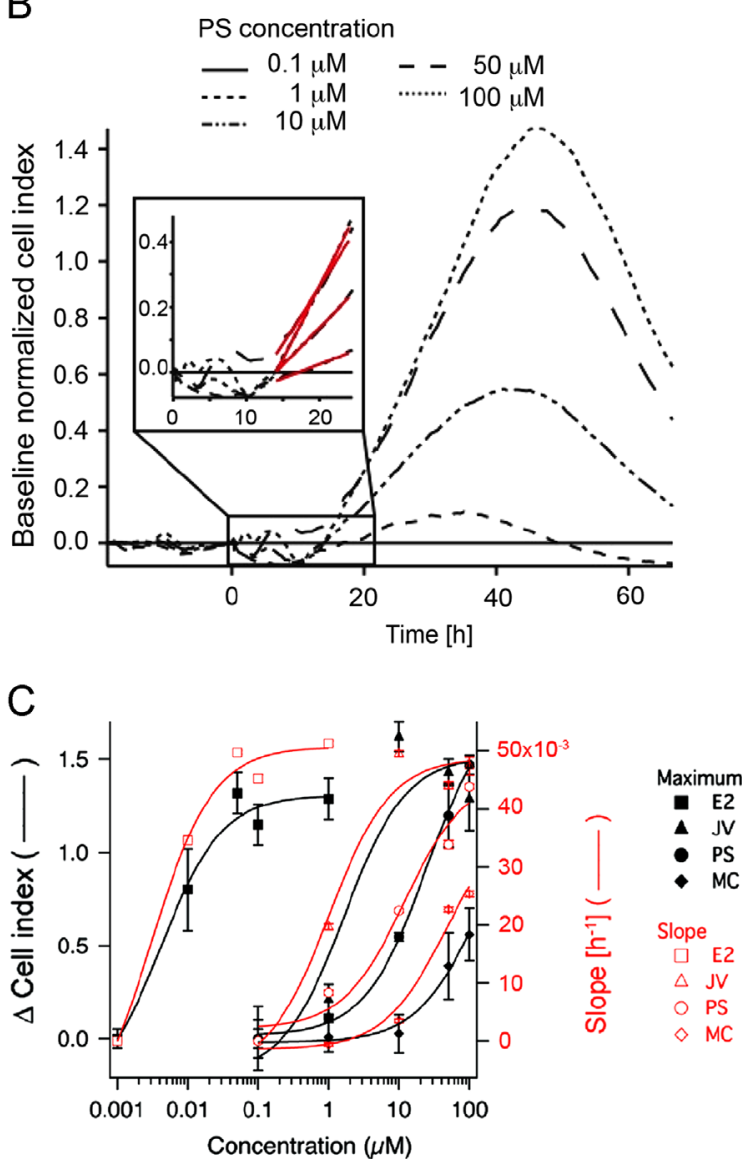

Fig. 2. Sensing the effect of different compounds on MCF7 cell proliferation by electrical impedance measurements. (A) The initial $\sim 20 \mathrm{~h}$ of recordings reflect the phase of cell attachment and spreading. Then electrical impedance measurements were performed for another $70 \mathrm{~h}$ after adding particular odorants and E2 at time "0" at the following concentrations: E2 $(0.1 \mathrm{nM})$, PS $(50 \mu \mathrm{M})$, JV $(50 \mu \mathrm{M})$, MC $(100 \mu \mathrm{M})$. Control measurements show the effect of adding cell medium or blocking the response of E2 by co-application of ICI 182,780 $(1 \mu \mathrm{M})$. Data represent means of at least three independent experiments $(+$ SEM). (B) Representative dose-dependent impedance measurements of MCF7 cell proliferation stimulated by Polysantol at the indicated concentrations. Cell Indices were normalized and baseline-corrected as described in the Materials and Methods section. Inset enlargement of the first ascending phase $(10-24 \mathrm{~h})$ poststimulation. (C) The slope of the initial ascending phase of the cell index versus time and impedance maxima generate almost identical concentration response curves. Full symbols represent concentration response curves obtained by plotting the maximal $\mathrm{Cl}$ values versus the corresponding compound concentration. Open symbols represent concentration response curves describing the slope of the early increase of cell indices versus time (Fig. 2B). Data represent means and standard deviations of at least three independent experiments.
After a small immediate increase, the impedance value remained at the same level for several hours until it rose again and reached an amplitude, which was significantly lower than that observed for the other compounds (Fig. 2A) suggesting that MC has lower estrogenic activity than PS and JV.

All impedance responses of MCF7 cells were found to be ER $\alpha$ selective. Co-application of the ER $\alpha$ selective antagonist ICI 182,780 , which strongly inhibited cell proliferation (Kariagina et al., 2010) also suppressed the impedance response for E2 (Fig. 2A) and all tested odorants (Fig. 3).

Next we analyzed which features of the impedance response could be quantified to evaluate dose-dependent effects of compounds on cellular responses. The curves were baseline-corrected and normalized as described in Section 2. Fig. 2B, shows baseline normalized cell index recordings of PS-mediated effects on MCF7 breast cancer cells as a function of odorant concentration. The maximum amplitudes of the cell indices, which were reached approximately $40 \mathrm{~h}$ after stimulation can be used to measure the concentration dependence of estrogenic effects (Fig. 2C).

A closer analysis revealed odorant dose-dependent differences in the slope of the early ascending phase of the impedance response initiated already $10-15 \mathrm{~h}$ after exposure to PS (Fig. 2B, inset). Moreover, the initial slope of the cell indices allowed the estrogenic effect to be quantified with a similar accuracy as when using the maximal amplitudes (Fig. 2C). In Fig. 3, the effect of E2 and all odorants could be detected already $10 \mathrm{~h}$ after stimulation, while the effect of the antagonist appeared immediate at the chosen time resolution $(<30 \mathrm{~min}$ ). This shows that estrogenic activities can be quantified considerably faster by impedance measurements than by classical cell proliferation assays.

The EC50 values of the different compounds obtained from ECIS compare well with data obtained from different biochemical tests (Pick et al., 2009). According to the impedance responses the signatures of JV and PS are characteristic of full agonists of ER $\alpha$. They elicit the same maximum response are the same as for E2, but their EC50 values are shifted to the micro-molar range, whereas MC has a distinctly smaller maximal effect.

\section{Discussion}

Some sandalwood odorants can have a profound effect on cell division in human breast cancer MCF7 cells (Pick et al., 2009). As proliferation of MCF7 cells is controlled by ER $\alpha$-mediated gene

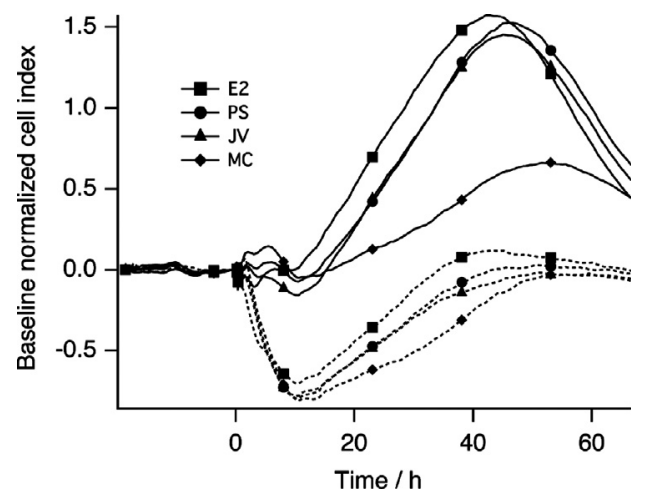

Fig. 3. Effect of the antagonist on the impedance response of MCF7 cells after stimulation by odorant fragrances. Impedance response of MCF7 cells after stimulation by odorants $(100 \mu \mathrm{M})$ and E2 $(1 \mathrm{nM})$ in the presence (dashed lines) and in the absence (continuous lines) of the antagonist ICI 182,780 $(1 \mu \mathrm{M})$. The antagonist fully blocks the impedance response of the cell proliferation for the 4 tested compounds at the concentrations used. In addition the antagonist induces an immediate and transient decrease of impedance before any effect of odorants can be detected. 
regulation (Soto et al., 1995; Hu et al., 2011) we analyzed the timecourse of odorant-induced transcription of ER $\alpha$ regulated genes in mitogenic and developmental processes. We characterized the time point of onset of transcriptional responses to subsequently relate these processes to early measurable phenotypic outcomes for the development of rapid assay readouts. RT-PCR revealed quite immediate odorant influences on gene transcription, which were detectable $\sim 1 \mathrm{~h}$ after application. Only recently it has been shown that E2 significantly affects a large fraction of the MCF7 transcriptome ( $\sim 26 \%$ ) within $1 \mathrm{~h}$ of treatment (Hah et al., 2011). Here, we provided the first evidence that the rapid transcriptional activation of ER $\alpha$ by specific odorant molecules is similar to the effect evoked by E2 in MCF7 cells.

The gene expression pattern induced by the odorants was very similar to that observed with E2. Highest up-regulation was measured for the progesterone receptor (PR), a ligand-activated nuclear transcription factor that promotes expression of genes involved in various signaling pathways of female reproduction (Graham and Clarke, 2002). Both PR and ER control normal breast development and are implicated in the etiology of breast cancer (Brisken and O'Malley 2010). The functional impact of PR in promoting MCF7 cell proliferation has been proven elsewhere (Chen et al., 2012).

Sandalwood odorants also up-regulated human amphiregulin (AR), a ligand for the epidermal growth factor receptor (EGFR) essential for mammary gland development (Busser et al., 2011). It induces proliferation of mammary glands upon estrogen and progesterone stimulation and activates the ERK, Akt and JNK signaling pathways to regulate cell proliferation (Kariagina et al., 2010).

Finally, we also observed odorant-mediated up-regulation of the wingless-type MMTV integration site family, member 4 (Wnt4) transcript. Wnt signaling is involved in multiple developmental processes as well as in breast cancer cell proliferation (Hu et al., 2011). Furthermore, Wnt4 expression is mediated in an ER $\alpha$ dependent manner (Brisken et al., 2000). The down-regulation of ER $\alpha$ transcription by E2 is established (Frasor et al., 2004) and we have shown here that the odorants regulate this gene in the same way as the natural ligand.

The time span between the initiation of ER $\alpha$-mediated gene expression and the resulting cellular phenotypic changes is poorly characterized, and might take several hours. We have shown here that ECIS can be used to shed light on these processes. As a central finding we observed that sandalwood odorants induced significant changes in cellular activities of MCF7 cells, which could be measured by increased impedance starting between 10 and $15 \mathrm{~h}$ after stimulation. This impedance response was odorant dose dependent and inhibited by the antiestrogen ICI 182,780 indicating that these effects were mediated by ER $\alpha$. Transcript levels induced by odorants were high at about $8 \mathrm{~h}$ after induction, as shown by our RT-PCR measurements. This result implies that a certain level of gene activation is required to cause subsequent cellular responses. We have demonstrated here that ECIS is capable of monitoring early cellular processes in response to endogenous ER $\alpha$ activation. This finding is important as it allows a much faster determination of estrogenic activities of chemicals compared to conventional MCF7 cell proliferation assays which in turn will accelerate the selection of compounds for further analyses focusing on their impact on human health. Our quantitative cellular response measurements provide information not only on the time frame of activation but also on the character of the ligand.

Only a few volatile compounds with estrogenic activity have yet been reported and sparse knowledge exists about their impact on transcription regulation. A recent study showed up-regulation of a single marker gene by benzylphenylmethylpropional (Lilial, commercially used in perfumes) in MCF7 cells at concentrations similar to those used in our present study (Charles and Darbre 2009; Pick et al., 2009), We provide here initial evidence for extended regulatory activities of synthetic odorants on a set of ER $\alpha$-dependent genes suggesting potentially broad influences of these compounds on cellular processes. While we have shown that sandalwood odorants modify gene transcription rapidly, reaching amplitudes comparable to those elicited by E2, significantly lower effects were reported for Lilial. Furthermore, transcription modulation by this odorant was only detected after longer exposure times ( $\sim 24 \mathrm{~h}$ ) (Charles and Darbre 2009). Some polycyclic musk fragrances exhibited anti-estrogenic effects in cell proliferation (Schreurs et al., 2005), while a small number of nitro musk fragrances slightly increased the rate of MCF7 cell divisions. For all of these substances, the estrogenic potency was low compared to E2 (Bitsch et al., 2002). Elsewhere, we have shown that sandalwood odorants substantially increased MCF7 proliferation to a similar extent as E2 but at elevated concentrations (Pick et al., 2009). This further underscores their role as ER $\alpha$-specific agonists.

Several thousands of yet uncharacterized chemicals might interfere with ER functions. A remaining challenge is to show why a range of structurally diverse chemicals can mimic estrogenic actions. To this end we have demonstrated that our methodology delivers information-rich impedance response profiles on kinetics, strengths and duration of cellular responses induced by activated ER $\alpha$. This allows the potency of estrogenic compounds to be quantified and compared to the natural hormone. More systematic research needs to be done to reveal and to dissect which specific impedance profile features may be indicative of partial or full agonist or antagonist responses on ER $\alpha$.

It is difficult to speculate whether or not single odorant compounds may reach sufficient concentrations to produce an estrogenic response in native breast tissues. Experimental findings show at least that lipophilic odorant molecules accumulate and concentrate in human adipose tissue and in human breast milk (Rimkus and Wolf, 1996). Such an enrichment of diverse estrogenic compounds might create an estrogenic burden with adverse effects on human health (Soto et al., 1995). Different estrogenic compounds may act in a synergistic manner on the modulation of ER $\alpha$ activity, where each compound alone would have only little effect (Evans et al., 2012). The possibility that various cellular activities can be integrated in the impedance measurements should make ECIS useful for investigating such cumulative effects on ER $\alpha$. Furthermore, since ECIS is a label-free method, it is ideally suited to analyze primary cells: to monitor for instance cancer development related to ER $\alpha$ as well as to functionally characterize other complex cellular signaling processes.

\section{Conclusions and future perspectives}

Our studies have shown that particular synthetic sandalwood odorants widely used in perfumes and fragranced body care products, rapidly activate ER $\alpha$-mediated gene expression resulting in the promotion of cell proliferation in hormone-sensitive human MCF7 breast cancer cells, which demonstrates their estrogenic activity. Compared to the long duration of conventional proliferation assays lasting over several days, we show that electrical cellsubstrate impedance sensing (ECIS) is a new method, which substantially accelerates the detection and quantification of proliferative responses in MCF7 for the screening of estrogenic chemicals.

To date a few hundreds of man-made chemicals are known to possess estrogenic activity. However, thousands of other chemicals have not been tested but are anticipated to potentially modulate natural hormonal systems in human or wildlife species (Rotroff et al., 2013). National and international governments specifically in 
USA, Japan, EU and other OECD countries are in the process of establishing testing programs to assess the safety of currently used chemicals regarding their hormone disrupting potential (Hecker and Hollert, 2011). Combining our non-invasive ECIS approach with modern microfluidic devices will facilitate such comprehensive screenings of chemicals for determining not only their estrogenic activities but very general their cytotoxic effects, which from legal commercial, medical and environmental aspect will become increasingly important in the future.

Furthermore, as our approach integrates all cellular activities into single real-time measurements, it also provides a promising strategy for analyzing the regulation of complex ER $\alpha$ signaling networks, opening new possibilities for studying the role of this receptor in physiological and cancer processes.

In a different way, the ECIS technique can be used to address the heterogeneity of tumor cells, which is of utmost importance for the analysis of tumor behavior in response to therapy. Recent reports have revealed the metastatic potential of different cell lines (Tarantola et al., 2010) and the acquired drug resistance of MCF7 cells (Eker et al., 2013). Through further electrode miniaturization, ECIS could be extended to the single-cell level offering new possibilities in cancer diagnosis.

\section{Acknowledgments}

The authors thank Ana Soto (Tufts University Boston, USA) for providing the MCF7 human breast cancer cell line. This work was supported by the Swiss National Science Foundation (SystemsXCINA), and internal funding from the EPFL.

\section{Appendix A. Supporting information}

Supplementary data associated with this article can be found in the online version at http://dx.doi.org/10.1016/j.bios.2013.06.052.

\section{References}

Abba, M.C., Hu, Y., Sun, H., Drake, J.A., Gaddis, S., Baggerly, K., Sahin, A., Aldaz, C.M. 2005. BMC Genomics 6, 37.

Agatonovic-Kustrin, S., Turner, J.V., Glass, B.D., 2008. Journal of Pharmaceutical and Biomedical Analysis 48, 369-375.

Ayyanan, A., Laribi, O., Schuepbach-Mallepell, S., Schrick, C., Gutierrez, M., Tanos, T. Lefebvre, G., Rougemont, J., Yalcin-Ozuysal, O., Brisken, C., 2011. Molecular Endocrinology 25, 1915-1923.
Bitsch, N., Dudas, C., Korner, W., Failing, K., Biselli, S., Rimkus, G., Brunn, H., 2002. Archives of Environmental Contamination and Toxicology 43, 257-264.

Brisken, C., Heineman, A., Chavarria, T., Elenbaas, B., Tan, J., Dey, S.K., McMahon, J.A., McMahon, A.P., Weinberg, R.A., 2000. Genes and Development 14, 650-654.

Brisken, C., O'Malley, B., 2010. Cold Spring Harbor Perspectives in Biology 2. a003178.

Brzozowski, A.M., Pike, A.C., Dauter, Z., Hubbard, R.E., Bonn, T., Engstrom, O., Ohman, L., Greene, G.L., Gustafsson, J.A., Carlquist, M., 1997. Nature 389 753-758.

Busser, B., Sancey, L., Brambilla, E., Coll, J.L., Hurbin, A., 2011. Biochimica et Biophysica Acta 1816, 119-131.

Charles, A.K., Darbre, P.D., 2009. Journal of Applied Toxicology 29, 422-434.

Chen, Y.J., Hung, C.M., Kay, N., Chen, C.C., Kao, Y.H., Yuan, S.S., 2012. Cancer Letters 319, 223-231.

Ciarloni, L., Mallepell, S., Brisken, C., 2007. Proceedings of the National Academy of Sciences of the United States of America 104, 5455-5460.

Conzen, S.D., 2008. Molecular Endocrinology 22, 2215-2228.

Creighton, C.J., Cordero, K.E., Larios, J.M., Miller, R.S., Johnson, M.D., Chinnaiyan, A. M., Lippman, M.E., Rae, J.M., 2006. Genome Biology 7, R28.

Eker, B., Meissner, R., Bertsch, A., Mehta, K., Renaud, P., 2013. PLoS One 8, e57423. Evans, R.M., Scholze, M., Kortenkamp, A., 2012. PLoS One 7, e43606.

Fang, H., Tong, W., Perkins, R., Soto, A.M., Prechtl, N.V., Sheehan, D.M., 2000. Environmental Health Perspectives 108, 723-729.

Frasor, J., Stossi, F., Danes, J.M., Komm, B., Lyttle, C.R., Katzenellenbogen, B.S., 2004. Cancer Research 64, 1522-1533.

Giacinti, L., Claudio, P.P., Lopez, M., Giordano, A., 2006. Oncologist 11, 1-8.

Giaever, I., Keese, C.R., 1991. Proceedings of the National Academy of Sciences of the United States of America 88, 7896-7900.

Graham, J.D., Clarke, C.L., 2002. Breast Cancer Research 4, 187-190.

Hah, N., Danko, C.G., Core, L., Waterfall, J.J., Siepel, A., Lis, J.T., Kraus, W.L., 2011. Cell $145,622-634$.

Hecker, M., Hollert, H., 2011. Environmental Sciences Europe 23, 15.

Hu, Z.Z., Kagan, B.L., Ariazi, E.A., Rosenthal, D.S., Zhang, L., Li, J.V., Huang, H., Wu, C., Jordan, V.C., Riegel, A.T., Wellstein, A., 2011. PLoS One 6, e20410.

Kariagina, A., Xie, J., Leipprandt, J.R., Haslam, S.Z., 2010. Hormones and Cancer 1, $229-244$.

Kininis, M., Kraus, W.L., 2008. Nuclear receptor signaling 6, e005.

Marino, M., Galluzzo, P., Ascenzi, P., 2006. Current Genomics 7, 497-508.

Metivier, R., Penot, G., Hubner, M.R., Reid, G., Brand, H., Kos, M., Gannon, F., 2003. Cell 115, 751-763.

Pick, H., Jankevics, H., Vogel, H., 2007. Journal of Molecular Biology 374, 1213-1223.

Pick, H., Etter, S., Baud, O., Schmauder, R., Bordoli, L., Schwede, T., Vogel, H., 2009. Journal of Biological Chemistry 284, 30547-30555.

Rimkus, G.G., Wolf, M., 1996. Chemosphere 33, 2033-2043.

Rotroff, D.M., Dix, D.J., Houck, K.A., Knudsen, T.B., Martin, M.T., McLaurin, K.W., Reif, D.M., Crofton, K.M., Singh, A.V., Xia, M., Huang, R., Judson, R.S., 2013. Environmental Health Perspectives 121, 7-14.

Schreurs, R.H., Sonneveld, E., Jansen, J.H., Seinen, W., van der Burg, B., 2005. Toxicological Sciences 83, 264-272.

Soto, A.M., Sonnenschein, C., Chung, K.L., Fernandez, M.F., Olea, N., Serrano, F.O., 1995. Environmental Health Perspectives 103 (Suppl. 7), 113-122.

Tarantola, M., Marel, A.K., Sunnick, E., Adam, H., Wegener, J., Janshoff, A., 2010. Integrative Biology (Cambridge) 2, 139-150.

Thomas, C., Gustafsson, J.A., 2011. Nature Reviews Cancer 11, 597-608.

Yu, N., Atienza, J.M., Bernard, J., Blanc, S., Zhu, J., Wang, X., Xu, X., Abassi, Y.A., 2006. Analytical Chemistry 78, 35-43. 